\title{
DETERMINATION OF PERFORMANCE EVALUATION OF MOBILE MANUFACTURING UNITS (MMUS) FOR SURFACE MINES: AN OEE APPROACH
}

\author{
G. Agyei ${ }^{1, *}$ and O. A Wettey ${ }^{2}$ \\ 1, Department of Mining EngineERING, University of Mines and TeChNology, Box 237, TarkWA, GHANA. \\ 2, African Explosives GhanA LTD., Former GNTC, HARbour AREA, TARKWA, GHANA \\ E-mail addresses: ${ }^{1}$ gagyei@umat.edu.gh, ${ }^{2}$ obedwettey@gmail.com
}

\begin{abstract}
For the measurement of overall equipment effectiveness, it is necessary to determine the magnitude of the types of production losses in order to plan activities and allocate resources effectively. The application of Overall Equipment Effectiveness (OEE) in Mobile Manufacturing Units for mining operations have not been duly adopted. There is the need to do the assessment of maintenance performance indices like availability and utilisation for improvement in productivity. This paper seeks to determine the maintenance performance indices like availability and utilisation of Mobile Manufacturing Units (MMUs) of African Explosives Limited (AEL) operations at Goldfields Ghana Limited, Damang. It was determined that the availability and utilisation were $93.55 \%$ and $30.61 \%$ respectively. The results obtained can contribute to the knowledge about the solution for improvement in scheduling of mine operations and the efficient monitoring of controllable factors that enhance maximum availability and utilisation of MMUs.
\end{abstract}

Keywords: Explosive, equipment, availability, utilization, maintenance, manufacturing

\section{INTRODUCTION}

African Explosives Limited (AEL) is a developer, producer and supplier of commercial explosives, initiating systems and blasting services for mining, quarrying and construction markets in Africa and some selected international markets. Goldfields Ghana Limited, Damang Mine has awarded contract to AEL to efficaciously supply explosives and services for its blasting activities.

A specially designed truck mostly known as the Mobile Manufacturing Units (MMUs) load, transport and pump the required explosives for blasting the in-situ rock at Damang Mine. The MMUs play a major role in the blasting processes. It is important to know the availability and utilisation of these trucks because they have significant impacts on production indices.

The aim of this paper is to determine the availability and effective utilisation of MMUs in order to improve upon the factors that lead to maximum availability and utilisation of MMUs at AEL Mining Services, Damang Mine.

Literature review in performance assessment of Mobile Manufacturing Units (MMUs) are essentially focused on the measurement of availability and utilization. Availability and utilization are important assessment tools for Overall Equipment Effectiveness (OEE). OEE is a performance indicator for production and productivity. The OEE concept can bring all equipment availability and utilization indices under an integral and general index. The OEE has been comprehensively used as a good performance indicator to evaluate how efficient a manufacturing unit employ its resources. OEE concepts as used in manufacturing and the mineral extraction takes into consideration all type of losses in speed, time, product and quality. A gamut of publications demonstrate the application of OEE concepts in the manufacturing indicators [1 - 3].

The conceptual applicability of OEE in the excavation and mining is found in $[4,5]$. Mohammadi, et al [6]

* Corresponding author, tel: +233-245-821- 539 
translated the concept of OEE to evaluate Bucket Based Excavation, Loading and Transport Equipment (BELT) and identified that the OEE of BELT equipment is dependent on availability, speed and bucket factors, corroborating with $[1,7]$. However, the Mobile Maintenance Unit in the mining industry has limited adoption of OEE as a good performance indicator. The concept of OEE and its application has not been fully realised in the mining industry. Given the holistic approach offered by OEE, there is the need to apply the OEE concept by proposing the appropriate methods and tools for measurement of OEE in Mobile Manufacturing Units for explosives in the surface mining operations. Findings from [7] proposes the concept of the performance of machines and equipment in manufacturing industries that takes into consideration the analysis of availability, utilisation and production losses as shown in Fig. 1.

The proposal of Nakajima defines OEE as directly proportional to availability, performance and quality rates as expressed in Eq. (1):

$$
Q E E=A \times P R \times Q
$$

In (1), $A$ is availability, PR is performance rate and $Q$ is quality. Fig. 1 depicts that any time component of the operating system is affected by three losses like downtime, speed and quality losses.

Deductions from Fig. 1 shows that OEE can be expressed as in Eq. (2) as follows;

$$
O E E=\frac{\text { Valuble Operating Time }}{\text { Loading Time }}
$$

Jeong and Philips [1] considered the calculation of OEE using the calendar time in contrast to Nakajima's method which is centred on the loading time. The factors considered for the calculation of OEE using [1] are shown in Fig. 2.

$$
\text { OEE }=\frac{\text { Valuble Production Time }}{\text { Total Calender Time }}
$$

However, the Mobile Manufacturing Unit in the mining industry has very limited adoption of OEE as a good performance indicator. The concept of OEE and its application has not been fully realized in the use of MMU's in the mining industry.

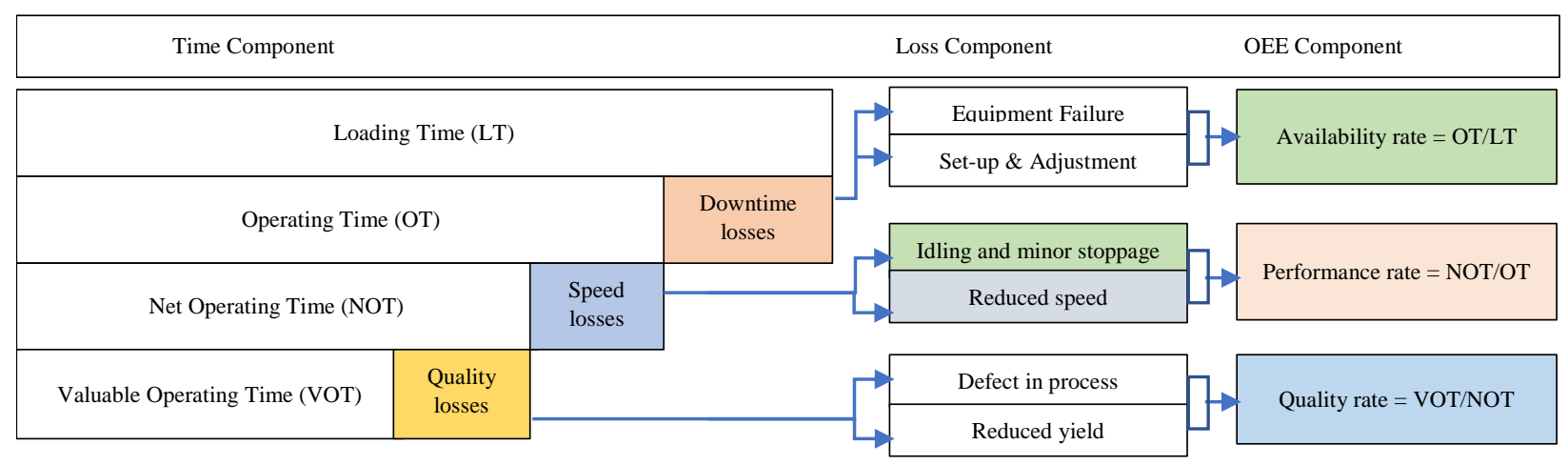

Fig.1 The OEE fundamental components according to Nakajima (After [7] in [6])

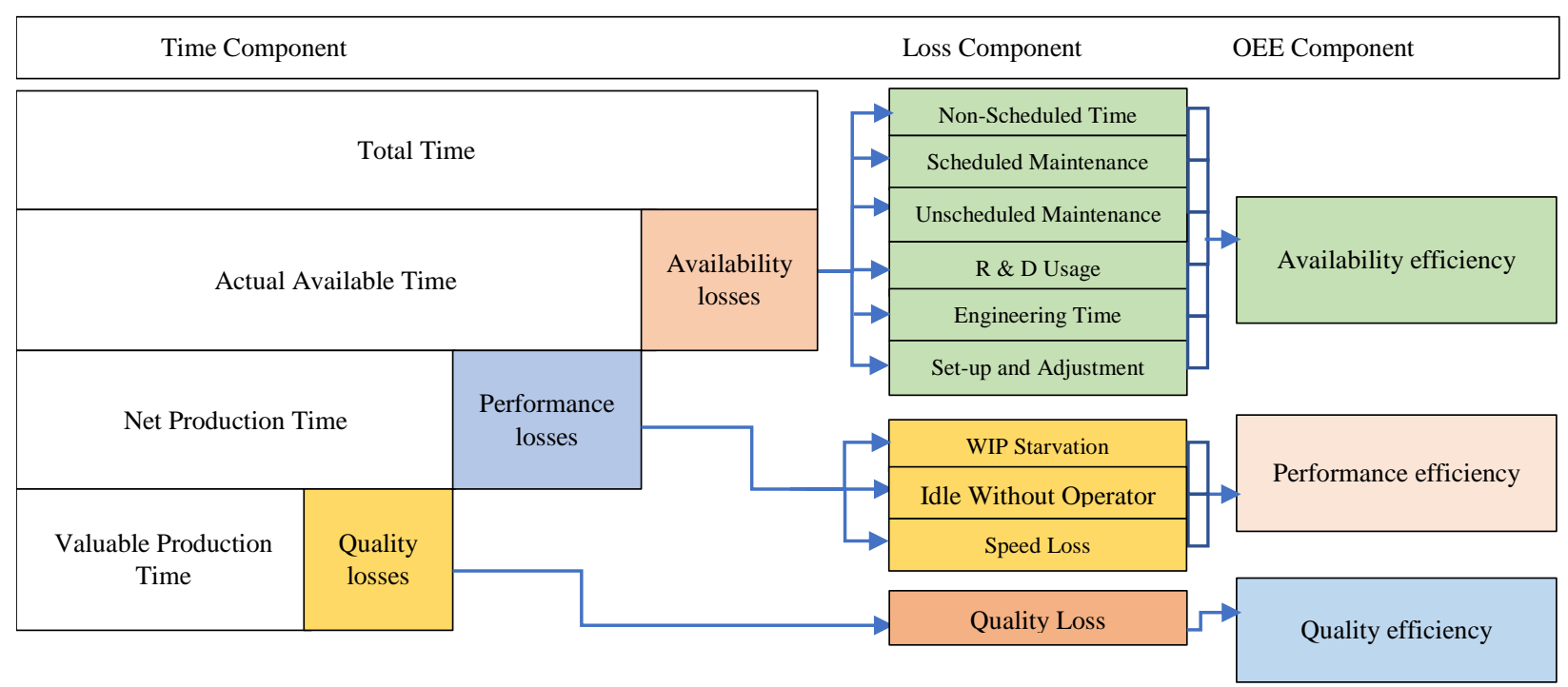

Fig. 2 The OEE factors according to Jeong and Phillips ([1] in [6]) 
Given the holistic approach of the OEE and its practical applications, the aim of this research is to translate the concept of OEE for MMU's equipment by introducing the appropriate methodologies and tools for measurement of OEE in MMU's in large side mining operations.

\subsection{Mobile Manufacturing Units}

Mobile Manufacturing Units (MMUs) are specially designed trucks which deliver explosives especially when there is the need to deliver explosive directly to the bench been drilled with blast in an active mining operation and to prepare the explosive compound so as to pump into the blast hole on site. In effect, mobile manufacturing units are explosive factory on wheels that are designed to produce and deliver specified bulk explosives from a manufacturing unit based on a conventional truck chassis. They are enhanced with mechanised means for loading bulk emulsion explosives into blastholes at high discharge rates, the loading is usually carried out by either auguring, pouring, pumping or pneumatically blowing emulsion explosives into blastholes. The method used depends on the type of product and the size of the blastholes to be filled.

These robust MMUs provided by AEL Mining Service are designed to withstand harsh environmental conditions encountered during normal mining operations. Design parameters include all necessary safety control systems, ease of operation, maintenance and reliability. Larger MMUs can deliver hundreds of tonnes of emulsion explosives in a single run at a loading rate of between 70 and $1000 \mathrm{~kg}$ per minute.

\subsection{Availability and Utilisation of Mobile Manufacturing Units}

Availability is the proportion of scheduled time equipment is mechanically conditioned (after mechanical and electrical repairs, preventive and servicing) so as to be used for its intended purpose [4; 8]. It is a considerate factor to understand this parameter as it reflects the decrease in scheduled time due to mechanical and electrical delays. A delay for a mechanical, electrical failure or repair; thus, includes worn out part replacement and welding as well as significant repair work. It does not, however incorporate the time for blundered transportation of parts or repair work. Availability of an equipment can be determined using Eq. 4 given as:

$$
\text { Availability }(\%)=\frac{O T-P D-U D}{O T} \times 100
$$

In (4), OT is the Operation Time which is the total time available for operation during the period (shift, day, week, month, etc.), Planned Downtime, PD is the time the equipment is not available to produce results based on scheduled events such as set-up time, adjustment time, employee breaks, scheduled maintenance, and shop floor meetings. Unplanned downtime (UD) is the time the equipment is not available to produce results based on unscheduled events such as corrective maintenance (mechanical and electrical or pumping), idling and minor stoppages.

According to [9], availability is deduced in percentages. In order to calculate the availability of equipment, some principal elements such as total hours inside the shift, breakdown hours and planned maintenance are being considered throughout the calculation process. Eq. 5 is used in the computation of availability.

$$
\text { Availability }(\%)=\frac{\text { Total Hours }- \text { Planned Ma intenace }}{\text { Total Hours }} \times 100
$$

According to Taylor [10], maintenance is grouped into:

i. Planned maintenance; and

ii. Breakdown maintenance.

\subsubsection{Planned maintenance}

Planned maintenance is defined by Taylor [10] as a program of periodic inspection to prevent breakdowns prior to its occurrence. It incorporates all the redundant servicing, upkeep and upgrades of equipment. Preventive maintenance and scheduled maintenance are the well-known types of planned maintenance. Preventive maintenance is pertinent to equipment or procedures where the cost of replacing an equipment itself is high, the efficiency of the unit or quality of the product is influenced or the time required to replace the unit is lengthy.

\subsubsection{Breakdown maintenance}

Breakdown maintenance is defined as the practices of repairing a machine or unit after it has broken down or stopped operating due to a mechanical or an electrical failure [10].

The availability of an equipment varies according to the following:

i. Working hours to be used in a shift;

ii. Effectiveness of preventive maintenance;

iii. Age of the equipment; and

iv. Difficulty of the working condition. 
Table 1: MMUs Availability and Utilisation for 2017

\begin{tabular}{llll}
\hline Month & $\begin{array}{l}\text { Average Working } \\
\text { Time }(\mathrm{min})\end{array}$ & $\begin{array}{l}\text { Availability } \\
(\%)\end{array}$ & $\begin{array}{l}\text { Utilisation } \\
(\%)\end{array}$ \\
\hline January & 12070 & 93.47 & 15.60 \\
February & 15810 & 99.56 & 26.47 \\
March & 14790 & 99.05 & 24.80 \\
April & 15810 & 95.98 & 33.80 \\
May & 14790 & 100.00 & 29.82 \\
June & 15810 & 98.62 & 34.85 \\
July & 15810 & 95.51 & 23.76 \\
August & 15300 & 92.09 & 29.12 \\
September & 15300 & 96.11 & 34.23 \\
October & 17670 & 93.80 & 35.16 \\
November & 15675 & 74.03 & 46.19 \\
December & 17400 & 84.33 & 33.51 \\
\hline
\end{tabular}

\subsection{Materials and Methods Used}

In accordance with the contract between $\mathrm{AEL}$ and Goldfields, Damang Mine, 10-hour per day shift system of which the MMUs have to be available was enacted. That is, from 7:00 am to $5: 00 \mathrm{pm}$ for that particular year. This was enacted because there was too much waiting time on the bench. In this contract, monthly data concerning shift availability and utilisation factors is provided to the client. These factors were taken into account in order to determine how they affect the availability and utilisation of the MMUs during the production year. In order to do this, field data collected from the daily MMU log sheets were input into an already programmed Microsoft Excel sheets. These known factors used for the determination of the MMUs availability and utilisation included the pumping time, working time in a month, maintenance time (preventive maintenance and service maintenance) and breakdowns.

The daily MMU Loading Report which were being filled by the operators provided the necessary field data needed for the calculation of the availability of the MMUs at Damang mine. This collected data is transferred unto a programmed Microsoft Excel sheet from which the availability and utilisation were obtained. The availability and utilisation of the MMUs for a working month is obtained by finding the average value of the availability and utilisation of each MMU on site.

Three MMUs were used from the beginning of the year, one MMU was later added to make four MMUs on site at the latter part of the same year to ensure effective operation. In all, the MMUs were MMU 27, MMU 33, MMU 34 and MMU 37. The availability and utilisation factors helped in the various computations, also the value of the total working month was averaged. Equations (7) and (10) were used in the computation of the shift availability and shift utilisation in the various months. Table 1 illustrates the availability and utilisation data for 2017 production year after the computations were done.

\subsubsection{Availability monitoring}

At AEL Mining Services, Damang mine field data for computation of availability and utilisation was acquired by the use of a daily log sheet. These log sheets were filled and put together by the MMU operators during each shift. This was done to demonstrate what the MMU did in a specific time during the shift of the day. The following are some characterised terms and activities embraced by the MMU during and at a specific time. This information is likewise shown on the day to day log sheet of the MMU:

i. Prestart check: This is a daily inspection made on the MMU to ensure that the equipment is in the right mechanical condition before it is put to use

ii. Travelling: Movement of MMU from station to the mine and back to the station.

iii. Waiting on site: The time the MMU awaits instruction from customer in the mine after it has been dispatched and has arrived on the bench.

iv. Loading: Time when emulsion, ANPP and the sensitiser is being loaded unto the MMU.

v. Waiting on bench: Time at which MMU awaits at the working face for customer to free choked holes or prime empty holes.

vi. Breakdown: Absence of the MMU due to mechanical, technical, electrical or pumping failure.

vii. Operating: Operation of the MMU on the bench.

viii. Planned maintenance: This maintenance is prior by arrangement with operations that is, it is scheduled.

ix. Stand-by: An MMU which is available and ready to work but has not being assigned to a blast field.

\subsubsection{Filling of the daily MMU log sheets}

Under a particular contract terms, every mine has its own shift systems under which activities in the mine are undertaken. In view of this, AEL Damang Site engages in a 10-hour per day shift, although the Daily MMU Log sheets were intended for 14 hours. Upon the signed contract between AEL and its client, the MMUs 
must be accessible for 10 hours; from 7:00 am to 5:00 pm. On the Daily MMU Log Sheet, every hour was isolated into four quarters suggesting that the operator of the MMU ticked what the MMU did in every 15 minutes from the beginning of shift to end of that shift. Sections have been assigned for waiting details, pumping breakdown details, other breakdown details and general remarks were included.

\subsubsection{Computation of availability}

In computation of availability, two variations were considered at AEL Mining Services; the shift and the bench availability. It is expressed as a percentage.

\subsubsection{Bench availability}

This was mainly concerned with the availability of the MMUs on a particular bench. Some factors considered under bench availability (BA) included; time used to wait on the bench, free choked holes, prime empty drill holes and pump the bulk explosive into the blast holes. Eq. 6 was used to compute bench availability.

$$
B A=\frac{W b+F+P r+P u}{W b+F+P r+P u+M b+E b+P b} \times 100
$$

where $\mathrm{Wb}$ is waiting on bench time, $\mathrm{F}$ is freeing the chocked holes time, $\mathrm{Pr}$ is priming time, $\mathrm{Pu}$ is pumping time, $\mathrm{Mb}$ is mechanical breakdown time, $\mathrm{Eb}$ is electrical breakdown time and $\mathrm{Pb}$ is pumping breakdown time.

\subsubsection{Shift Availability}

Shift availability (SA) was determined by the availability of the MMU during the 10-hour shift. Breakdown time and maintenance were being deducted from the total shift hours in a month. The acquired value is then divided by the total number of shift hours per month. Eq. 7 was used to compute shift availability.

$$
S A=\frac{(W d \times 10 \times 60)-(M b+E b+P b+s+P m)}{W d \times 10 \times 60} \times 100
$$

where $\mathrm{Wd}$ is working days, $\mathrm{Mb}$ is mechanical breakdown time, Eb is electrical breakdown time, $\mathrm{Pb}$ is pumping breakdown time, $\mathrm{S}$ is service time and $\mathrm{Pm}$ is preventive maintenance time.

Utilisation is defined as the proportion of the scheduled time that an available equipment is used for its intended purpose. The said equipment should operate at its full potential under this condition. Utilisation is calculated as a percentage of available hours. Under the competency of the mine personnel, efficiency of the mine planner and the support equipment commitment, the utilisation of a particular unit can vary.

According to Dampson [2], Eq. 8 is used to calculate utilisation of equipment:

$$
\text { Utilization }(\%)=\frac{T H-D H-S H}{T H-D H} \times 100
$$

In (8), TH is the total hours, DHis the downtime hours and $\mathrm{SH}$ is the standby hours. Total hours are the number of hours in a shift, downtime hours are the number of hours used for scheduled and unscheduled maintenance and standby hours are the number of hours the MMU is available to work but has not been allocated to a bench.

\subsubsection{Computation of Utilisation}

In computation of utilisation, two variations were considered at AEL Mining Services; the shift and the bench utilisation. It was expressed as a percentage.

\subsubsection{Bench Utilisation}

It denotes the activities of the MMU on an assigned bench. The bench waiting time, free choked holes, prime empty drill holes and pump the bulk explosive into the blast holes were taken into consideration in other to determine the utilisation of the MMU on that particular bench. Eq. 9 was used in computation of the bench utilisation (BU).

$$
B U(\%)=\frac{P u}{W b+F c+P r+P u} \times 100
$$

where $\mathrm{Pu}$ is pumping time, $\mathrm{Wb}$ is time used to wait on bench, Fc is time used to free chocked holes and $\mathrm{Pr}$ is the time used to prime empty hole.

\subsubsection{Shift Utilisation}

The relation below was used to compute shift utilisation Eq. 10 was used in computing shift utilisation (SU) during the MMU's operation.

$$
\boldsymbol{s U}(\%)=\frac{P u}{10 \times 60 \times W d(M b \times P b \times E b \times S \times P m)} \times 100
$$

where $\mathrm{Pu}$ is pumping time, Wd is working days, Eb is electrical breakdown time, $\mathrm{Pb}$ is pumping breakdown time, $\mathrm{S}$ is servicing time and $\mathrm{Pm}$ is preventive maintenance time.

\section{RESULTS AND DISCUSSION}

\subsection{Shift Availability and Target Availability}

Fig. 1 shows the availability achieved during 2017 production year against the set target of $85 \%$. It can be deduced from Fig. 1 that the target was met by AEL's MMUs except for the months of November and December. The target was missed by $10.97 \%$ and $0.67 \%$ respectively as a result of high breakdown of 
the MMUs experienced during these months. A total breakdown time of 115 hours was experienced during these months. May had the highest availability of $100 \%$ since no breakdown was experienced. February, March and June also recorded higher availabilities as well due to low breakdown times.

\subsection{Breakdown Time}

Table 2 shows the compiled percentage of breakdowns time of the total working time during the production year. This involves the mechanical, electrical and pumping breakdowns during the working month.

From Table 2, the months of February and May recorded no breakdown values. However, November had the highest value of 68 hours and this was as a result of pumping and mechanical breakdowns of MMUs 27, 33 and 34. The month of December also had a high value of 48 hours as a result of mechanical and pumping breakdowns. The months of January, March, April, June, July September and October also recorded breakdown times less than 17 hours.

\subsection{Maintenance Time}

Maintenance time involves both servicing and preventive maintenance times during the working month, and these factors are paramount in the computation of shift availability and shift utilisation. Table 3 illustrates the maintenance time (servicing and preventive maintenance time) for each month.

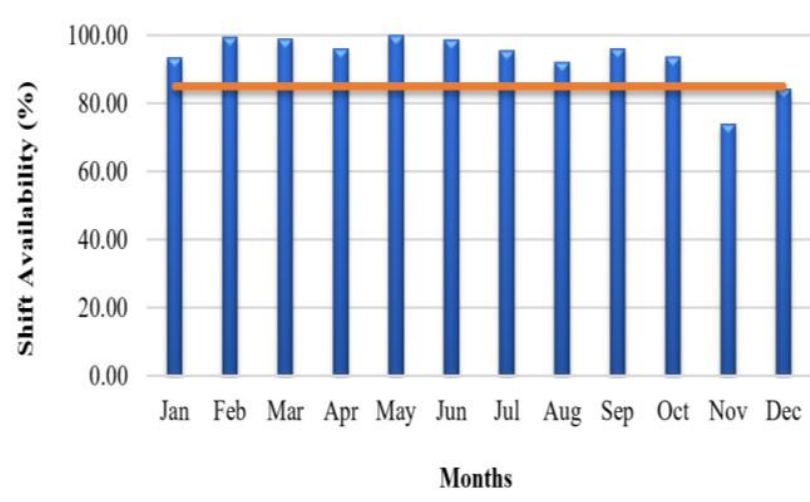

Fig. 1 Comparing Achieved Availability and Target Availability

Table 2 Percentage Expression of Breakdowns Time of Total Working Time

\begin{tabular}{lccccc}
\hline \multirow{2}{*}{ Month } & $\begin{array}{c}\text { Average Working } \\
\text { Time }(\mathrm{min})\end{array}$ & $\begin{array}{c}\text { Time } \\
(\mathrm{min})\end{array}$ & $\begin{array}{c}\text { Breakdowns } \\
\text { \% of Average } \\
\text { working Time }\end{array}$ & $\begin{array}{c}\text { Availability } \\
(\%)\end{array}$ & $\begin{array}{c}\text { Utilisation } \\
(\%)\end{array}$ \\
\cline { 3 - 4 } & 12070 & 220 & 1.82 & 93.47 & 15.60 \\
January & 15810 & 0 & 0.00 & 99.56 & 26.47 \\
February & 14790 & 20 & 0.14 & 99.05 & 24.80 \\
March & 15810 & 565 & 3.57 & 95.98 & 33.80 \\
April & 14790 & 0 & 0.00 & 100.00 & 29.82 \\
May & 15810 & 95 & 0.60 & 98.62 & 34.85 \\
June & 15810 & 710 & 4.49 & 95.51 & 23.76 \\
July & 15300 & 1110 & 7.25 & 92.09 & 29.12 \\
August & 15300 & 595 & 3.89 & 96.11 & 34.23 \\
September & 17670 & 850 & 4.81 & 93.80 & 35.16 \\
October & 15675 & 4072 & 25.98 & 74.03 & 46.19 \\
November & 17400 & 2854 & 16.40 & 84.33 & 33.51 \\
December & & & & &
\end{tabular}

Table 3 Percentage Expression of Maintenance Time of Total Working Month

\begin{tabular}{|c|c|c|c|c|c|}
\hline \multirow[b]{2}{*}{ Month } & \multirow{2}{*}{ Average Working Time (min) } & \multicolumn{2}{|c|}{ Maintenance } & \multirow{2}{*}{ Availability (\%) } & \multirow{2}{*}{ Utilisation $(\%$} \\
\hline & & Time (min) & $\%$ of Average working Time & & \\
\hline January & 12070 & 180 & 1.49 & 93.47 & 15.60 \\
\hline February & 15810 & 210 & 1.33 & 99.56 & 26.47 \\
\hline March & 14790 & 360 & 2.43 & 99.05 & 24.80 \\
\hline April & 15810 & 210 & 1.33 & 95.98 & 33.80 \\
\hline May & 14790 & 0 & 0.00 & 100.00 & 29.82 \\
\hline June & 15810 & 150 & 0.95 & 98.62 & 34.85 \\
\hline July & 15810 & 0 & 0.00 & 95.51 & 23.76 \\
\hline August & 15300 & 300 & 1.96 & 92.09 & 29.12 \\
\hline September & 15300 & 0 & 0.00 & 96.11 & 34.23 \\
\hline October & 17670 & 390 & 2.21 & 93.80 & 35.16 \\
\hline November & 15675 & 540 & 3.44 & 74.03 & 46.19 \\
\hline December & 17400 & 135 & 0.78 & 84.33 & 33.51 \\
\hline
\end{tabular}


It can be deduced from Table 3 that, the time for maintenance did not substantially affect availability of the MMUs as recorded in the months of February, May, July and September. However, extremely higher maintenance time resulted in lower availability as recorded in the month of November as a result of mechanical and pumping breakdown of MMU 27, 33, and 34. Subsequently, the month of March, August and October also had values less than 7 hours.

\subsection{Pumping Time}

An important factor to consider in computation of utilisation is the pumping time of the MMUs. This involves the time at which explosives are being loaded into the blastholes. Table 4 shows the percentage of the pumping time with its corresponding utilisation in the working months.

It could be observed from Table 4 that, higher pumping time within a working month resulted in higher utilisation as well. The month of November recorded the highest percentage pumping time of $43.06 \%$ corresponding to utilisation of $46.19 \%$. The least recorded pumping time occurred in the month of January with utilisation of $15 \%$ and percentage pumping time of $19.76 \%$.

\subsection{Available Time Lost}

The time at which the MMU is unavailable to perform its intended task at a given time is defined as the available time lost. It is critical to analyse how this factor affects the availability of the MMU. It was computed by summation of the time lost due to breakdowns and maintenance. Table 5 shows data of the available time lost in the working months.

Table 5 indicates that the month of May had no lost time resulting in $100 \%$ availability. However, November recorded the highest percentage lost time of $26.20 \%$ as a result of extremely high breakdown time of 68 hours. The months of August and December relatively also had high available time losses. It can be deduced that, months with higher percentage available time lost have lower availabilities as compared with those having lower percentage available time lost.

Table 4 Pumping Time Expressed as a Percentage of Total Monthly Working Time

\begin{tabular}{cccccc}
\hline Month & Average Working Time $(\mathrm{min})$ & Pumping Time $(\mathrm{min})$ & \% of Average Working & Availability (\%) & Utilisation (\%) \\
\hline January & 12070 & 2385 & 19.76 & 93.47 & 15.60 \\
February & 15810 & 4185 & 26.47 & 99.56 & 26.47 \\
March & 14790 & 3668 & 24.80 & 99.05 & 24.80 \\
April & 15810 & 5175 & 32.73 & 95.98 & 33.80 \\
May & 14790 & 2940 & 19.88 & 100.00 & 29.82 \\
June & 15810 & 3623 & 22.91 & 98.62 & 34.85 \\
July & 15810 & 3735 & 23.62 & 95.51 & 23.76 \\
August & 15300 & 4178 & 27.30 & 92.09 & 29.12 \\
September & 15300 & 5063 & 33.09 & 96.11 & 34.23 \\
October & 17670 & 5310 & 30.05 & 93.80 & 35.16 \\
November & 15675 & 6750 & 43.06 & 74.03 & 46.19 \\
December & 17400 & 6608 & 37.97 & 84.33 & 33.51 \\
\hline
\end{tabular}

Table 5 Available Time Lost Expressed as a Percentage of Total Monthly Working

\begin{tabular}{ccccc}
\hline Month & Average Working Time $(\mathrm{min})$ & Availability $(\%)$ & Available Time Lost (min) & Percentage of Total Monthly Time \\
\hline January & 12070 & 93.47 & 840 & 6.96 \\
February & 15810 & 99.56 & 210 & 1.33 \\
March & 14790 & 99.05 & 420 & 2.84 \\
April & 15810 & 95.98 & 635 & 4.02 \\
May & 14790 & 100.00 & 0 & 0.00 \\
June & 15810 & 98.62 & 435 & 2.75 \\
July & 15810 & 95.51 & 710 & 4.49 \\
August & 15300 & 92.09 & 1210 & 7.91 \\
September & 15300 & 96.11 & 595 & 3.89 \\
October & 17670 & 93.80 & 970 & 5.49 \\
November & 15675 & 74.03 & 4106 & 26.20 \\
December & 17400 & 84.33 & 2989 & 17.18 \\
\hline
\end{tabular}




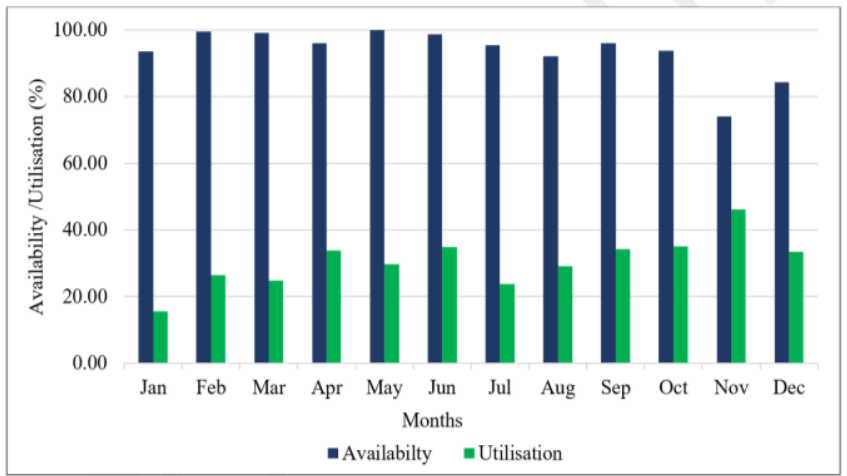

Fig. 2: Shift Availability and Corresponding Shift Utilisation

\subsection{Shift Availability and Shift Utilisation}

Fig. 2 indicates the shift availability with its corresponding shift utilisation in the working months. It can be clearly deduced from Fig. 2 that the values of percentage availability are higher as compared to their corresponding percentage utilisation.

The month of November recorded the highest utilisation whiles the month of January recorded the lowest utilisation. The low utilisation value recorded in that month was as a result of low pumping time of the MMUs working time within that month.[11] in their analysis about the impact of availability and utilisation of drill rigs found a strong correlation between average hours used by an equipment and productivity. To minimise breakdowns, the most reliable MMUs must be put on the more demanding jobs and less reliable ones on less demanding jobs. In computation for shift utilisation, factors such as time to load gassing, load water, load Ammonium Nitrate dense Prills, load diesel, travel to site and bench must be included since all these activities involves usage of the MMUs.

A utilisation target should be set for AEL by their client as this will serve as a check on how the MMUs are effectively utilised in each production year.

\section{CONCLUSION}

a) The application of Overall Equipment Efficiency (OEE) for the MMUs in a surface mine has yielded useful results to identify losses related to availability and utilisation.

b) This paper reviews the factors that are used in the computations of the trucks' availability and utilisation and how these factors affected the availability and utilisation.

c) The factors analysed were breakdowns, maintenance hour, pumping time and working time of the month. d) The total breakdown time experienced during the year 2017 was 185 hours corresponding to 5.96\% of the total working time;

e) The various computations for the Mobile Manufacturing Units did not include reliability factors;

f) The maintenance time for the year 2017 was 41 hours representing $1.33 \%$ of the total working time for the year; and

g) The pumping time for the year was 894 hours which also corresponds to $28.79 \%$ of the total working time.

\section{REFERENCES}

[1] Jeong, K.Y. and Phillips D.T. "Operational Efficiency and Effectiveness Measurement", .IJOPM, Vol.21, Number 11,2001 ,pp. 1404-1416.

[2] Anvari F., Edwards, R. and Starr A. "Methodology and theory evaluation of overall equipment effectiveness based on market, JQME 16(3), 2010, pp 256-270.

[3] Tsarouhas P.H. "Evaluation of overall Equipment effectiveness in the beverage industry", IJPR 51, 2, 2013, pp. 515-523.

[4] Dhilton B.S., 2008. Mining Equipment, Reliability Maintainability and Safety, Springer-Verlag London Limited, London.

[5]Elevli, S. and Elevli, B. "Performance Measurement of Mining Equipment by Utilizing OEE", Acta Montanistica SlovacaRocnik, 15(2,) 2010, pp. 95-101.

[6] Mohammadi, M., Rai, P. and Gupta, S. "Perfarmance evaluation of Bucket based Excavating, Loading and Transport Equipment", Arch. Min. Sci. 62, 1,2017, pp. 105-120.

[7]Nakajima, S. Introduction to TPM- total productive maintenance. Productivity, Cambrige Press, 1988.

[8]Sweigard, R. J. Materials Handling: Loading and Hauling, In Chapter 9.3 of SME Mining Engineering Handbook, Hartman H.L (ed.), 2nd Edition, Vol.1, SME, Port City Press, Inc. 1992.

[9]Dampson, K. Availability and Utilisation of Mobile Manufacturing Units at Orica Mining Services, Akyem Site Mine, Unpublished BSc Project Report, University of Mines and Technology, Tarkwa, 2015.

[10]Taylor, R. Equipment Maintenance, In Chapter 12.8 of SME Mining Engineering Handbook, Harman H.L. (ed), 2nd Edition, Vol. 1, SME, Port City Press, Inc., 1992.

[11]Kansake, B.A, and Suglo, R.S. "Impact of availability and utilisation of drill on production at Kanjorle Minerals Limited", International Journal of Science, Environment and Technology, Vol.4, No.6, 2015, pp. 1524-1537 